\title{
The Value of Saving Oil in Saudi Arabia
}

\author{
JORGE BLAZQUEZ, ${ }^{\mathrm{a}}$ LESTER C. HUNT, $^{\mathrm{b}}$ BALTASAR MANZANO, ${ }^{\mathrm{c}}$ and AXEL PIERRU ${ }^{\mathrm{d}}$
}

\begin{abstract}
Saudi Arabia has one of the highest levels of per capita oil consumption in the world, but attempts are now being made by Saudi policymakers to significantly reduce this. Thus, a relevant policy question is what is the value of saving a barrel of oil in Saudi Arabia? The instinctive answer is that the value saved is the difference between the international market price and the domestic price. However, for Saudi Arabia, this answer is insufficient for several reasons. First, the current administered domestic price of oil is set below international market levels, which leaves room for improved economic efficiency. Second, Saudi Arabia is not a marginal producer of oil but a critical player in the international oil market; a shift in Saudi exports affects international oil prices and consequently the country's revenue from oil exports. Third, there are different ways to reduce the domestic consumption of oil. This paper explores policies that reduce the domestic consumption of oil in Saudi Arabia, increasing the amount of oil that would ultimately be exported and assesses the impact on welfare and carbon emissions (however, given the long-run perspective adopted bere, it does not address the optimal timing to export the oil that is saved). Among the various methodologies to do this, we opt for a general equilibrium model. Our results suggest that oil-saving policies would lead to positive welfare gains and a reduction in domestic carbon emissions. The most relevant insight for policymakers is that a barrel of oil saved in the Saudi economy leads to an increase in welfare ranging between $\$ 6$ to $\$ 56$ for an international oil price of $\$ 52.9$ per barrel, depending on the policy, and a decrease in domestic $\mathrm{CO}_{2}$ emissions from $150 \mathrm{~kg}$ to $368 \mathrm{~kg}$.
\end{abstract}

Keywords: Oil saved, carbon emissions, welfare, policy cost, Saudi Arabia

https://doi.org/10.5547/2160-5890.9.1.jbla

\section{* 1. INTRODUCTION}

The Kingdom of Saudi Arabia is the largest oil exporting country and, at the same time, has one of the highest levels of oil consumption per capita - 44 barrels per year compared to 27 in the U.S. and 10 in the European Union. Moreover, the expansion in GDP per capita has been accompanied by a sharp increase in oil consumption, something that has not taken place in other rich economies. Figure 1 shows the evolution of GDP per capita and oil consumption per capita for the period 2000-2017 for the European Union, the U.S. and Saudi Arabia.

\footnotetext{
a The Oxford Institute of Energy Studies, United Kingdom. E-mail: Jorge.Blazquez@oxfordenergy.org

${ }^{\mathrm{b}}$ Economics and Finance, University of Portsmouth, United Kingdom, and King Abdullah Petroleum Studies and Research Center (KAPSARC), Saudi Arabia. E-mail: lester.hunt@port.ac.uk.

c Universidade de Vigo, Spain, and King Abdullah Petroleum Studies and Research Center (KAPSARC). E-mail: bmanzano@ uvigo.es

${ }^{\mathrm{d}}$ Corresponding author. King Abdullah Petroleum Studies and Research Center (KAPSARC), P.O. Box 88550, Riyadh 11672, Saudi Arabia. E-mail: Axel.Pierru@kapsarc.org
} 


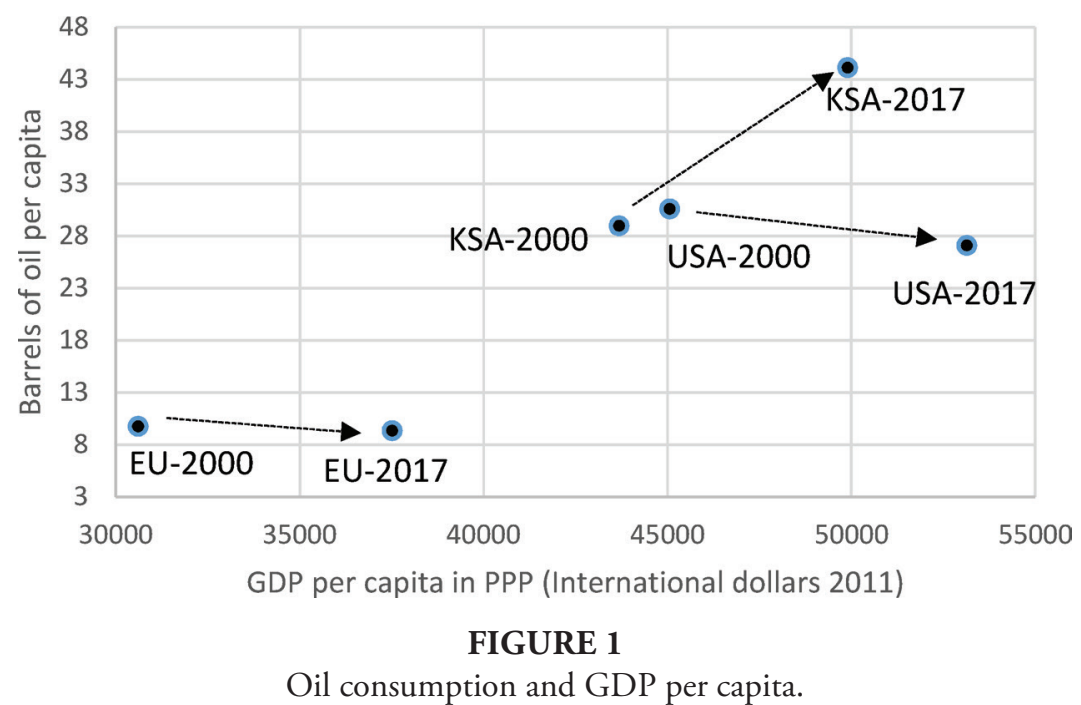

The average rate of growth of Saudi oil consumption between 2000 and 2017 was $5.4 \%$ per annum compared to a global average of $1.5 \%$ per annum. In this context of high oil consumption growth, Citigroup speculated in 2012 that Saudi Arabia might be a net oil importer by 2030 (Helman, 2012). One likely factor driving this high level of consumption is the low administered prices of domestic oil and oil products, the primary sources of electricity generation in Saudi Arabia (ECRA, 2015). Partly in recognition of this, and to curb domestic oil consumption, Saudi Arabia raised the price of 91 - and 95 -octane gasoline by about $67 \%$ and $50 \%$, respectively, in 2016 and, again, in January 2018 by about $80 \%$ and $125 \%$, respectively. Saudi Arabia also raised electricity prices for households and industries in 2016 (Council of Ministers' Decree dated 28/12/2015) and, again, in January 2018 (Council of Ministers' Decree dated 12/12/2017). The size of these increases in some cases exceeded 200\%, depending on households' electricity consumption. ${ }^{1}$ Furthermore, Saudi Arabia launched the National Renewable Energy Program to facilitate a shift in power generation from fossil fuels to renewable technology, with the aim of achieving 9.5 GW of installed capacity by 2023 (Renewable Energy Project Development Office, 2017).

Taking a long run perspective, this study attempts to answer the question, what is the value of a barrel of oil saved and instead exported? For a textbook economy, the marginal productivity of a barrel of oil across all activities and sectors would be equal to its market price. For Saudi Arabia, this implies that its marginal productivity would be lower than the international price, given the lower administered domestic prices of oil. The difference between domestic and international prices provides a means by which the country can allocate oil more efficiently among different activities and sectors.

This paper analyzes different policies with the aim of reducing domestic consumption of oil and thus increasing oil exports. The following policies are analyzed: increasing the share of natural gas in electricity generation; increasing the efficiency of natural gas power plants; deploying renewable technology; increasing the administered price of oil; implementing electricity efficiency programs; increasing the fuel efficiency of the transportation sector; and - for

1. Currently, the price of 91 -octane gasoline is $\$ 0.36$ per liter, the price of 95 -octane gasoline is $\$ 0.54$ per liter, and the price of electricity for residential consumers is $\$ 0.048$ per $\mathrm{kWh}$ or $\$ 0.08$ per $\mathrm{kWh}$ if their consumption exceeds $6,000 \mathrm{kWh}$ per month. 
the sake of completeness- increasing the production of oil. Any oil saved as a result of the policies could be exported immediately or left in the ground for future production. However, given the long-term perspective of our analysis, the optimal time strategy to export the oil is not considered here; although, adjusting the level of production to current and future market conditions is critical for maximizing the value of Saudi oil.

To explore the impact of these policies on a macroeconomic level, we use and extend a small open economy dynamic general equilibrium model for Saudi Arabia introduced by Blazquez et al. (2017). Saudi Arabia is a critical player in the international oil market and changes to its production or export policy can impact the market. Because of this, we expand the model by adding an oil price reaction function that links Saudi exports and international prices. Previous studies, such as De Santis (2003) and Nakov and Nuño (2013) consider the role of Saudi Arabia in determining international oil prices. More recently, Pierru et al. (2018) evaluate the impact of the Saudi spare capacity on the international oil price. We adapt the Blazquez et al. (2017) model to explore the potential macroeconomic gains from efficiency improvements in power generation and in the use of electricity and oil products. We also evaluate the net impact on domestic $\mathrm{CO}_{2}$ emissions of the different policies.

Computable general equilibrium models and dynamic general equilibrium models are increasingly used as standard research tools in energy economics. These models have been used to analyze the macroeconomic effects of energy price shocks ${ }^{2}$ and to analyze different policy options. ${ }^{3}$ Some studies have used these types of models to focus specifically on the impact of fossil fuel subsidies on the economy. Lin and Li (2012) explore the impact of China's energy subsidies on its competitiveness and carbon emissions. Wesseh and Lin (2017) explore the potential negative implications on welfare of removing fossil fuel subsidies in Ghana. Dartanto (2013) focuses on the link between fossil fuel subsidies and poverty in Indonesia. Schwanitz et al. (2014) discuss the impact of removing fossil fuel subsidies on the transition towards a cleaner energy mix and find that this policy could slow the global transition towards a renewable energy system. In the same context, Burniaux and Chateau (2014) show how removing subsidies for fossil fuels would bring environmental and economic benefits. However, oil-exporting countries would likely face real income reductions. Finally, Plante (2014) explores the impact of oil subsidies on the welfare of oil importing and oil exporting countries and finds that subsides distort relative prices and generate a welfare loss, suggesting the replacement of oil subsidies by lump-sum transfers.

Nevertheless, previous research has not specifically examined Saudi Arabia using macroeconomic general equilibrium models, except for Blazquez et al. (2017), who analyze renewable energy development and energy subsidies using a dynamic general equilibrium model, Gonand (2016) and Gonand et al. (2019), who analyze the impact of higher energy efficiency and of raising administered retail energy prices using an intergenerational macro model. Moreover, as far as we are aware, this study is the first to analyze the different policy initiatives in Saudi Arabia explicitly aimed at saving oil to increase exports. ${ }^{4}$

The paper is organized as follows. The next section outlines the framework for the analysis, followed by a discussion of the policy options considered (Section 3). Section 4 presents and discusses the simulation results. Section 5 summarizes and concludes.

2. For example, see Kim and Loungani (1992) and Rotemberg and Woodford (1996).

3. For example, see De Miguel and Manzano (2006) and Golosov et al. (2014).

4. Atalla et al. (2018) conduct a partial equilibrium analysis to estimate the potential net welfare gain from Saudi Arabia gasoline price increase in 2016. 


\section{* 2. ANALYSIS FRAMEWORK $\not$}

This paper extends the small open economy general equilibrium model for Saudi Arabia detailed in Blazquez et al. (2017). The model has a representative infinitely lived household that consumes energy services and a final good. The household offers labor inelastically in the domestic labor market and saves in domestic capital and foreign bonds. The Saudi Arabian government owns the primary energy resources in this economy, oil, and natural gas. Oil production is allocated (i) to power generation, (ii) to produce energy services, or (iii) to be exported. The administered domestic prices of oil are below the international price with market forces allocating domestic oil in different activities until the marginal productivities of all the activities are identical to the domestic price. Therefore, the government does not have oil quotas for different domestic activities. Natural gas production is sold domestically to the electricity company at an administered price.

The government owns the electricity company, which uses oil, natural gas, and renewable energy to produce electricity that it then sells to a competitive energy services firm. In the mod$\mathrm{el}$, the price of electricity for consumers is fixed to cover the costs, so there is no profit or loss. The energy services firm uses oil and electricity to produce energy services and sells the services to the household and to the firm that produces a final good. This representative firm uses labor, capital, and energy services to produce a final good that is sold to the household and exported. There is also an international market for bonds that allows the Saudi Arabian economy to run a current account deficit or surplus. The government collects revenues from oil, natural gas, and renewables, which finances renewable investments and transfers to the household. Figure 2 shows a schematic representation of the model.

We have extended the cited model in four ways. First, we consider the production of oil as a policy variable that can be changed. Second, the technical efficiency of natural gas power plants can be improved at a cost. Third, the energy services firm can increase the efficiency of oil and electricity at a cost. Finally, we add a price response function, linking the international price of oil to Saudi exports.

An on-line appendix describes the model and these extensions and specifies how it implements the different policies.

\section{* 3. POLICES TO SAVE AND EXPORT ADDITIONAL BARRELS OF OIL}

In this section, we describe the policies considered in the analysis; in particular, policies to reduce the domestic use of oil and carbon emissions in Saudi Arabia, leading to an increase in oil exports and, for the sake of completeness, an increase in oil production. A description of the policies considered precedes a discussion of the technical feasibility of scaling these policies. In all the policies we assume the following: first, exported oil is sold at the international price; second, the government directly finances the cost of each policy, having an impact on the public budget; third, the extra revenues from oil exports are transferred to households as a lump-sum transfer, and fourth, the policy is sustained over time. The policies considered are as follows ${ }^{5}$ :

5. We considered one additional policy: a change in aggregate productivity. We find that to reduce oil consumption, aggregate productivity of the economy would have to decrease. The analysis of this policy is discarded, since it is not reasonable to encourage a reduction in aggregate productivity to save oil. 


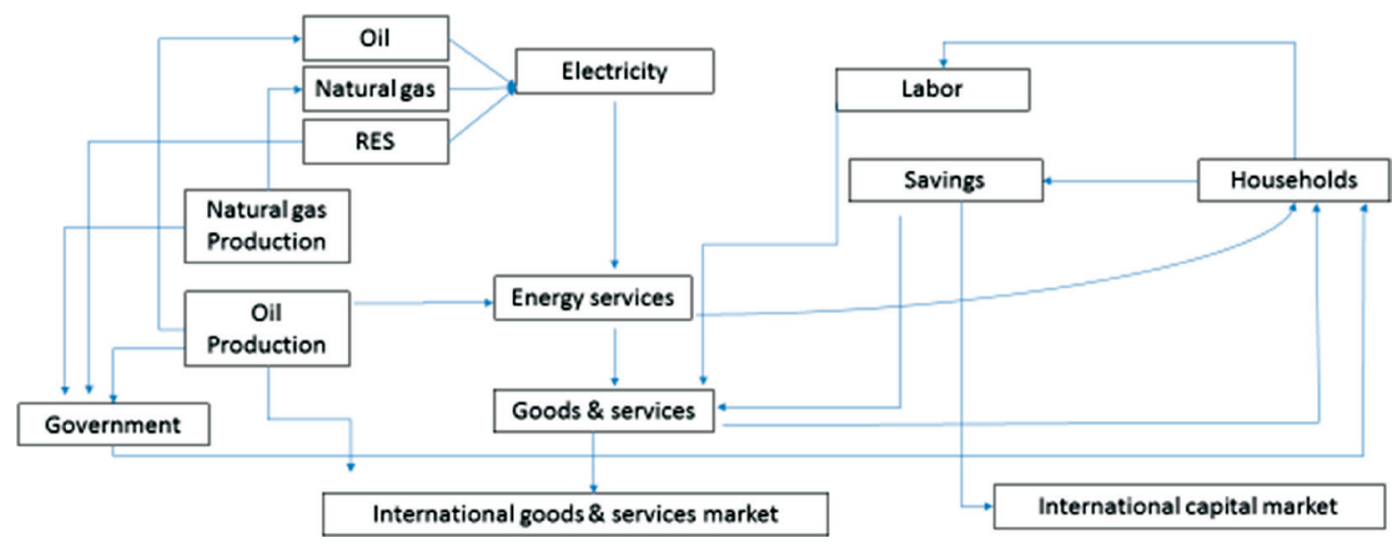

FIGURE 2

Graphical description of the analysis framework.

Policy 1: Increasing the production of oil:

This is arguably the most obvious policy to increase oil exports. The cost of this policy would be the additional investments and operational expenses needed to produce more oil. ${ }^{6}$ We assume that the cost of the policy is $\$ 9$ per barrel, a figure consistent with the Wall Street Journal $(2016)^{7}$ based on UCube Rystad Energy's oil and natural gas database.

In the model, we assume that the national oil company, Saudi Aramco, is integrated into the government so that all the revenues and costs of the oil company are part of the revenues and costs of the government. ${ }^{8}$

Policy 2: Increasing the share of natural gas electricity generation through LNG imports:

Electricity generation in Saudi Arabia currently relies heavily on oil. According to the Electricity and Cogeneration Regulatory Authority (2015), crude oil and oil products accounted for $68 \%$ of Saudi Arabia total electricity generation. This policy therefore considers Saudi Arabia importing liquefied natural gas (LNG) ${ }^{9}$ to generate electricity, displacing oil and oil products that can then be released for export. The estimated cost of LNG imports is $\$ 8.2$ per million British Thermal Units (MMBtu). ${ }^{10}$

Policy 3: Increasing the efficiency of natural gas power plants:

We assume that the calorific efficiency electricity generation from natural gas is 0.42 , implying that one calorific unit of natural gas is transformed into 0.42 calorific

6. We also assume that the current level of spare capacity of oil is held constant. In other words, Saudi Arabia will not increase production using its spare capacity.

7. There are other estimations for the cost of oil production. For example, the database knoema (https://knoema.com/rqaebad/ cost-of-producing-a-barrel-of-crude-oil-by-country) reports that the operating cost of oil production in Saudi Arabia is $\$ 5 / \mathrm{bbl}$.

8. It is worth noting that the Saudi government has announced the public flotation of $5 \%$ of Saudi Aramco but we assume in the model that this will make no material change to the current situation.

9. Most of the production of natural gas in Saudi Arabia is associated to oil production. This is why Saudi Arabia is considering the possibility of importing LNG. See Petroleum Economist (2017).

10. This price is an average of the estimated price in January 2018 of LNG imported from the U.S., Malaysia, and Indonesia. 
units of electricity (see Blazquez et al., 2017). It is possible to increase the calorific efficiency of natural gas power plants by investing in more efficient power plants, resulting in less oil being used for power generation.

We estimate that increasing the efficiency of a natural gas power plant by $1 \%$ requires an investment of $\$ 1,964$ per kilowatt hour $(\mathrm{kWh})$, with a maximum technical efficiency of 0.542 . This calculation is based on the cost and efficiency of three technologies: a natural gas combined cycle, an advanced natural gas combined cycle and an advanced combustion turbine, as reported by the U.S. Energy Information Administration (2016). ${ }^{11}$

Policy 4: Deploying renewable technology:

At the time of writing, there is no significant renewable generation in Saudi Arabia. Hence, in the base case scenario, all electricity is generated from oil and natural gas. However, it would be possible to deploy renewable technology in Saudi Arabia and reduce electricity generation from oil. We assume that the renewable technology is PV solar crystalline silicon cells with a cost $\$ 1,340,000$ per MW and a capacity factor of 19\% as suggested by Bloomberg New Energy Finance (2015).

Policy 5: Increasing the administered price of domestic oil:

This policy is probably the simplest way to reduce the domestic consumption of oil. Moreover, it does not imply any additional direct pecuniary cost to the government or any public company. In the model, the domestic price of oil and oil products are increased simultaneously and in the same proportion. It is important to note that in our model this policy implies an automatic increase in the price of electricity, given that oil is the main primary energy source used to produce electricity and the public electricity company transfers any cost increase to consumers through higher electricity prices. Finally, there is also an increase in the price of energy services.

Policy 6: Increasing the efficiency of electricity in energy services:

The same quantity of energy services (power, cooling, or lighting) can be produced using less electricity (and fewer inputs to produce the electricity) by investing in more efficient technologies.

The total cost of an electricity efficiency program includes, among other factors, direct rebates or incentives to customers, technical support, program administration, evaluation, verification, and marketing. Molina (2014) analyzes 20 different U.S. state electricity programs from 2009 to 2011, finding that the average cost of reducing electricity consumption by one $\mathrm{kWh}$ is $\$ 0.028$. This is the reference value we use as a benchmark.

11. In theory, it would also be possible to increase the efficiency of oil power plants by investing in more efficient generation technology. However, as far as we are aware, there is no available information about the cost of different oil plants at utility scale to produce electricity; hence, we do not analyze this policy. 
Policy 7: Increasing the efficiency of oil and oil products in energy services:

In this case, the primary energy service is transportation. The policy would maintain the quantity of energy services provided, such as distance travelled, but with less oil and oil products used. To achieve this, we explore two possibilities: Policy 7a, a car-scrapping program and Policy 76 , a hybrid program, assuming that for both policies the average life of a vehicle is 10 years. ${ }^{12}$

The Spanish scrapping program PIVE 8 (Instituto para la Diversificación y el Ahorro de Energía, 2017) is used as a benchmark for implementing Policy $7 a$. This program was used to scrap and replace over 290,000 old vehicles with new efficient vehicles with a budget of $€ 225$ million. To have access to public support, the new vehicle has to be at least $15 \%$ more efficient than the average new vehicle. In this paper, we assume that vehicles bought under the scrapping program are $15 \%$ more efficient than standard vehicles.

For Policy $7 b$, the hybrid program, it is assumed that conventional cars are replaced by hybrid cars. ${ }^{13}$ Based on Liu (2014), the hybrid car is assumed to be $26 \%$ more efficient in terms of fuel consumption and $17 \%$ more expensive.

Table 1 shows a comparison of the estimated cost of the policies, in constant 2016 dollars, to reduce oil consumption by one barrel. ${ }^{14}$

An important consideration is whether any oil saved would be exported immediately or left in the ground for future extraction and production. Our analysis focuses on the long-term impact of these policies and for this reason, we assume that any barrels of oil saved are exported since the structure of the model suggests that keeping barrels in the ground has a negative impact on oil revenues, public transfers to households, consumption and ultimately welfare. However, we recognize that adjusting the level of production to current and future market conditions is critical for maximizing the value of Saudi oil.

\section{TABLE 1}

Direct cost of the policies to export one additional barrel.

\begin{tabular}{lc}
\hline Policy & Cost $(\$)$ \\
\hline 1 Production of oil & 9.3 \\
2 Natural gas imports & 36.4 \\
3 Efficiency of gas power plants & 4.4 \\
4 Renewable technology & 16.4 \\
5 Price of domestic oil & 0 \\
6 Efficiency of electricity & 34.3 \\
7a Efficiency of oil (scrapping program) & 15.3 \\
7b Efficiency of oil (hybrid program) & 53.8 \\
\hline
\end{tabular}

12. IHS Global Insights (2010) points out that these schemes may generate unwanted distortions to the automotive market structure, reducing its potential benefits. Cuenot (2009) suggests that car-scrapping programs can incentivize the acquisitions of heavier or bigger cars, thereby reducing the efficiency of the programs.

13. We assume that hybrid cars do not include plug-in hybrids, as this would lead to a significant increase in electricity demand.

14. Educational policies could also play a role in curbing energy consumption. Hahn and Metcalfe (2016) point out that behavioral science is starting to offer some useful insights on how to design better policies, but these are not considered here. 


\section{* 4. SIMULATION RESULTS}

\subsection{Saving one barrel of oil}

For each policy, we initially consider the potential welfare effects of saving one barrel of oil and selling it on the international market. Policies may impact welfare through five different channels:

- A positive impact due to the gap between the domestic price and the international price of oil, which would be common across all policies since the increase in oil revenues is the same.

- A negative effect resulting from the reduction in the international oil price, which would be common across all policies.

- An increase in the productivity of the economy resulting from energy efficiency programs, adding an 'extra positive' welfare impact. These include Policy 6, Policy 7a, and Policy $7 b$ that aim to increase the efficiency of the use of electricity, oil, and oil products.

- A negative impact due to the specific cost of each policy.

- In the case of Policy 5, there is also a negative impact due to the increase in domestic energy prices.

It is important to note that, in the model, additional net public revenues from the different policies are transferred to the household by means of a non-distorting lump-sum transfer. In addition, our long-term approach does not capture short-term and transitional effects. In particular, some of the policies studied can be implemented immediately while others require prior investments or consumer behavioral changes that could take time. In addition, we do not consider short-term price dynamics with investment lags and strategic decisions concerning the best moment to sell the oil saved.

Table 2 summarizes the simulation results from considering saving one barrel of oil via all policies. This presents the estimates from the model for gross welfare gain without a price reaction; net welfare gain without a price reaction but taking into account the cost of the policies; net welfare gain with price reaction; the ranking of the policies; and the estimated impact on $\mathrm{CO}_{2}$ emissions. First, we assume that the policy has no cost and the barrel of oil saved has no impact on international markets, which implies that the additional barrel exported is sold at the international market price $(\$ 52.9$ per barrel). Using these assumptions, we estimate the gross welfare gains without a price reaction. Welfare gains are defined as the increase in expenditure in total private consumption, including energy services consumption, that leaves the representative household indifferent between the new situation and the initial situation before any policy is implemented. In our simulations, we assume that the current account is constant in absolute terms, while it changes in terms of GDP. In most business cycle studies, the current account relative to GDP is constant in steady state, while it changes in absolute terms. ${ }^{15}$ Second, we include the cost of each policy and estimate the societal net welfare gains, assuming a shift in Saudi exports does not affect the international oil price. Third, we relax this assumption and allow for an international oil price response by computing a long-run price elasticity of the residual demand for Saudi oil as explained in Pierru et al. (2018). Fourth, we

15. This decision is non-trivial in terms of welfare gains. Blazquez et al. (2017) calibrate the model assuming a trade surplus to GDP in real terms of $16 \%$. This implies that 16 cents out of every additional dollar from exports is saved and, then, is not consumed or invested domestically. Our less conventional approach assumes that additional revenues from exports are totally consumed or invested domestically. 
TABLE 2

Welfare gains and $\mathrm{CO}_{2}$ emissions of the policies per additional barrel exported (in 2016 dollars and kilograms).

\begin{tabular}{|c|c|c|c|c|c|}
\hline \multirow[b]{2}{*}{ Policy } & \multicolumn{2}{|c|}{ Without price reaction } & \multicolumn{3}{|c|}{ With price reaction } \\
\hline & Gross & Net & Net & Rank & $\mathrm{CO}_{2}$ \\
\hline 1 Production of oil & 53.7 & 42.0 & 31.5 & 4 & +10 \\
\hline 2 Natural gas imports & 53.7 & 15.9 & 5.6 & 8 & -150 \\
\hline 3 Efficiency of gas power plants & 53.7 & 46.6 & 38.1 & 2 & -368 \\
\hline 4 Renewable technology & 53.7 & 35.7 & 25.2 & 5 & -368 \\
\hline 5 Price of domestic oil & 28.6 & 28.6 & 18.2 & 7 & -368 \\
\hline 6 Productivity of electricity & 86.6 & 48.1 & 37.6 & 3 & -368 \\
\hline 7a Efficiency of oil (scrapping program) & 86.6 & 66.7 & 56.3 & 1 & -368 \\
\hline 7b Efficiency of oil (hybrid program) & 86.6 & 29.0 & 18.7 & 6 & -368 \\
\hline
\end{tabular}

rank the policies according to the net welfare gains with price reaction and show the reduction in domestic $\mathrm{CO}_{2}$ emissions.

As we are using a general equilibrium framework, the results account for all the direct and indirect impacts, including any implicit rebound effects. For example, to increase the exports of oil in Policy 1 by one barrel, production has to increase by 1.04 barrels. The additional barrel exported implies higher revenues for the country, leading to higher demand for electricity and oil products by consumers and firms. This explains why the gross welfare gain of an additional barrel exported without a policy cost and without a price reaction is not identical to the international price of oil. The country exports one barrel at the international price (\$52.9), and 0.04 barrels are sold domestically at the administered price $(\$ 18)$, giving a total of $\$ 53.7$. Thus, the welfare gain of producing one additional barrel of oil is $\$ 53.7 / 1.04=\$ 51.6$.

Regarding net welfare gains with price reaction, Policy 1 is arguably the most intuitive way to increase oil exports. However, as Table 2 shows, this does not produce the largest estimated welfare gain, being ranked $4^{\text {th }}$. Table 2 also shows that Policy 1 is the only policy that leads to an increase in domestic carbon emissions, as no oil is actually 'saved.' Policy $7 a$ has the highest estimated welfare gain and produces the highest estimated reduction in emissions, as most of the policies considered other than Policy 1 and Policy 2; this is despite Policy $7 a$ not being the cheapest. The reason for this result is that, in our model, the private consumption of goods and energy services are the two drivers of welfare. A car scrapping program allows a simultaneous increase in non-energy consumption and energy services.

Policy 6 and Policy $7 b$ have a direct impact on the efficiency of the energy services firm and have the greatest positive impact on gross welfare. However, as Table 2 shows, the cost of the policies is an important aspect when considering their viability. For example, Policy $7 b$ is ranked $7^{\text {th }}$ in terms of net welfare gains due to its high cost negating its positive effects, whereas Policy 6 is ranked $3^{\text {rd }}$ in terms of net welfare.

Policies 2, 3 and 4 aim to reduce the consumption of oil and oil products in electricity generation. Table 2 shows that Policy 3 is quite attractive in terms of net welfare gains (ranked $2^{\text {nd }}$ ) while Policy 2 and Policy 4 have lower estimated net welfare gains (ranked $8^{\text {th }}$ and $5^{\text {th }}$ ) due to their higher costs.

Policy 5 also increases the electricity price, as oil is the most relevant input in electricity generation. This policy has no fiscal cost but has indirect negative implications for consumers, given the increase in the prices of energy services and the reduction in the production of final goods. Despite this, Policy 5 is estimated to result in an overall societal net welfare gain but is ranked $7^{\text {th }}$. 
The simulation results provide four key insights relevant for Saudi policymakers ${ }^{16}$ :

- Policies aimed at marginally curbing oil consumption have a positive impact on welfare and carbon emissions.

- Shifting from oil to natural gas in electricity generation has a mild positive impact on welfare and carbon emissions, although incremental natural gas is assumed to be imported.

- Considering an international oil price response lowers the welfare gain from exporting an additional barrel by $\$ 10.2$ in average (under our price elasticity assumptions).

- The 'value' of a barrel of oil saved in Saudi Arabia ranges between \$5.6 to \$56.3.

This study focuses on the Saudi Arabian economy; we therefore only report the evolution of domestic $\mathrm{CO}_{2}$ emissions under different policies. However, according to the model, there is a decrease in the international price of oil due to the increase of Saudi exports, which disincentives oil production in the rest of the world: the supply of oil from the rest of the world reduces by 0.7 barrels per day and international emissions decrease by $260 \mathrm{~kg}$.

\subsection{Technical feasibility of escalating policies above one barrel}

The previous sub-section discusses the potential impacts from Saudi Arabia saving one barrel of oil a day and exporting it. In reality, Saudi policymakers are likely to want to save and export more than just one barrel per day. Therefore, we need to consider the technical feasibility of escalating the amount of oil saved and exported for all the policies analyzed in this paper. Consequently, in this sub-section, we explore the feasibility of increasing oil exports by 75,000 barrels per day (bpd) and 375,000 bpd, which represent around $1 \%$ and $5 \%$ of oil exports, respectively.

According to the Saudi Arabian Monetary Authority (2016), oil production varied between 8.2 million bpd and 10.2 million bpd in the period 2006-2015. This suggests that Saudi Arabia can easily adjust its crude oil production according to prevailing oil market conditions. Therefore, there would be no technical constraints hindering a significant escalation above one bpd for Policy 1. There is also no technical constraint regarding Policy 5 since, in theory, this policy has no technical limit; it would be possible to increase domestic prices of oil above international prices, like many oil importing countries with heavy taxes on fossil fuels. Thus, for Policy 1 and Policy 5, Saudi Arabia should not encounter any technical constraints. However, there could be non-technical issues such as resistance from other OPEC members for Policy 1 and problems with the implicit social contract with Policy 5. These issues are not considered here.

Other than Policy 1 and Policy 5, all other policies considered would have technical constraints when escalating significantly above one bpd. Policy 2 has a technical limit of $100 \%$ penetration of natural gas power generation in the electricity system, which implies that oil has been totally displaced from power generation. According to our estimates, the technical limit of this policy would be $696,000 \mathrm{bpd}$.

16. Welfare analysis is the standard way to evaluate polices. Nevertheless, policymakers also find the impact on GDP and the public budget to be relevant. We conduct a simulation analysis to assess the impacts on these variables. We find that Policy 5 has the largest positive impact on public revenues, but the smallest impact on GDP. The reason is that the increase in the domestic price of oil boosts public revenues but disincentives non-energy domestic production. Policies $6,7 a$, and $7 b$ improve productivity and, as a result, increase GDP significantly. However, the high cost of these policies has a strong detrimental effect on public revenues. 
The average technical efficiency of natural gas power plants is 0.42 , while the technical limit is 0.54 , which would save $102,000 \mathrm{bpd}$. Increasing oil exports by 75,000 bpd would require a technical efficiency of 0.51 , which is technically feasible. However, to increase oil exports by 375,000 bpd gas power plants would need to achieve an efficiency of 0.86 , which is not feasible.

In the case of Policy 4 , the penetration of renewable generation needed to save and export $75,000 \mathrm{bpd}$ is $7 \%$, which is reasonable. For example, wind and solar generation in the European Union was 13\% of total net production of electricity in 2016 (BP, 2017). Policy 3 has a technical limit of $67 \%$ of penetration in the electricity system (ECRA, 2015), which implies that oil would be totally displaced from power generation. In practice, given that Saudi Arabia lacks any significant hydro generation (BP, 2017), we impose an upper bound of 35\%, identical to the ambitious target approved in January 2018 by the European Union Parliament for 2030. This renewable penetration would save $367,000 \mathrm{bpd}$, slightly below the target of 375,000 bpd.

Policy 6 implies a substantial change in efficiency to achieve the required effect on oil exports. To export 75,000 additional bpd, electricity efficiency would have to increase by $19 \%$. This increase is an ambitious objective. For example, Boogen (2017) finds an average inefficiency of around $20 \%$ to $25 \%$ for Swiss households. This range captures the engineering inefficiency of the appliance stock, but also the inefficiency that can be avoided through household behavioral changes. To export 375,000 additional bpd, efficiency would have to increase by $158 \%$ - which is unlikely to be achieved. Following Boogen (2017), we assume that the limit for this policy is $25 \%$, which would save $96,000 \mathrm{bpd}$.

To increase oil exports by 75,000 bpd, the efficiency of the complete Saudi fleet would have to increase by $13 \%$, which is feasible for both Policy $7 a$ and Policy $7 b$. According to Liu (2014), the energy efficiency of a hybrid vehicle is $26 \%$ higher than a conventional vehicle. This increase in efficiency would save around 139,000 bpd, implying that 375,000 bpd is not feasible for either policy. We assume the technical limit for Policy $7 a$ at 15\% (see Instituto para la Diversificación y el Ahorro de Energía, 2017) and 26\% for Policy 7b, as discussed above. Policy $7 a$ and Policy $7 b$ would displace, at their maximum scalability, 82,000 bpd and 139,000 bpd respectively.

Table 3 summarizes these findings and categorizes policies into three groups: 'Feasible', in that the target could be achieved by implementing the policy; 'Technically feasible', where it would be difficult to achieve in practice, given that the increase in efficiency needed to achieve the target is close to the technical limit of the policy; 'Not feasible' i.e., not technically possible.

TABLE 3

Scalability of the programs.

\begin{tabular}{lcc}
\hline Policy & Target 75,000 bpd & Target 375,000 bpd \\
\hline 1 Production of oil & Feasible & Feasible \\
2 Natural gas imports & Feasible & Feasible \\
3 Efficiency of gas power plants & Technically feasible & Not feasible \\
4 Renewable technology & Feasible & Technically feasible \\
5 Price of domestic oil & Feasible & Feasible \\
6 Productivity of electricity & Feasible & Technically feasible \\
7a Productivity of oil (scrapping) & Feasible & Not feasible \\
7b Productivity of oil (hybrids) & Feasible & Not feasible \\
\hline
\end{tabular}




\subsection{Impacts of escalating policies from one bpd to $75,000 \mathrm{bpd}$}

Given that Table 3 highlights the limited policy options of being able to increase oil exports by $375,000 \mathrm{bdp}$, we focus on the lower figure of 75,000 bpd since it is feasible for all policies. Although this figure is towards the upper end of feasibility for some policies, it allows for a clear comparison across all policies considered. The results from the analysis for net welfare gains, GDP, net public revenues, and the impact on domestic $\mathrm{CO}_{2}$ emissions are detailed in Table 4 (note that the ranking of the policies in terms of net welfare is the same as that in Table 2).

The main insight from Table 4 is that saving 75,000 bpd in Saudi Arabia (for policies 2 to 7b) increases net welfare and reduces carbon emissions. Table 4 suggests that Policy 3 would result in relatively high welfare gains but, as explained previously, it would not be easy to achieve

\section{TABLE 4}

Annual impacts of the policies to increase oil exports by 75,000 bpd (in billion 2016 dollars and million tons).

\begin{tabular}{lcccc}
\hline Policy & Net welfare & GDP & Net public revenues & $\mathrm{CO}_{2}$ \\
\hline 1 Production of oil & 0.9 & 1.2 & 0.9 & +0.3 \\
2 Natural gas imports & 0.2 & 0.2 & 0.2 & -4.1 \\
3 Efficiency of gas power plants & 1.0 & 1.2 & 1.0 & -10.1 \\
4 Renewable technology & 0.7 & 1.2 & 0.7 & -10.1 \\
5 Price of domestic oil & 0.5 & 0.3 & 1.5 & -10.1 \\
6 Productivity of electricity & 0.9 & 2.2 & -0.3 & -10.1 \\
7a Productivity of oil (scrapping) & 1.5 & 2.3 & 0.3 & -10.1 \\
7b Productivity of oil (hybrids) & 0.4 & 2.2 & -0.9 & -10.1 \\
\hline
\end{tabular}

the 75,000 bpd target with this policy. From a policymaker's standpoint, Policy 7a, Policy 6 and Policy 4 are the best policies as they are easy to escalate, they would increase net societal welfare and reduce domestic $\mathrm{CO}_{2}$ emission by 10 million tons annually. The disadvantage of Policy 6 is that its high cost has a detrimental effect on public revenues. For Policy 5 , the analysis suggests that the domestic price of oil needs to increase by $5.5 \%$ to save $75,000 \mathrm{bpd}$, but would result in a high positive impact on net public revenues. Thus, despite the price rises for consumers, the higher revenues for the government could increase the appeal of this policy for policymakers. Finally, these policies could also be attractive to Saudi policymakers from an environmental perspective, since each policy from 3 to $7 b$ would reduce total domestic $\mathrm{CO}_{2}$ emissions ${ }^{17}$ by $1.6 \%$, and Policy 2 would reduce them by $0.6 \%$.

Figure 3 represents the impacts of the policies in terms of welfare, public revenues, and GDP. It clearly shows that policies which have a positive impact on productivity have a large positive impact on GDP but deliver lower public revenues. Policies that reduce the share of oil in the power mix produce higher public revenues but at the cost of a smaller positive impact on GDP. Finally, a policy that increases the domestic price of oil boosts public revenues but the increase in GDP is more limited. 


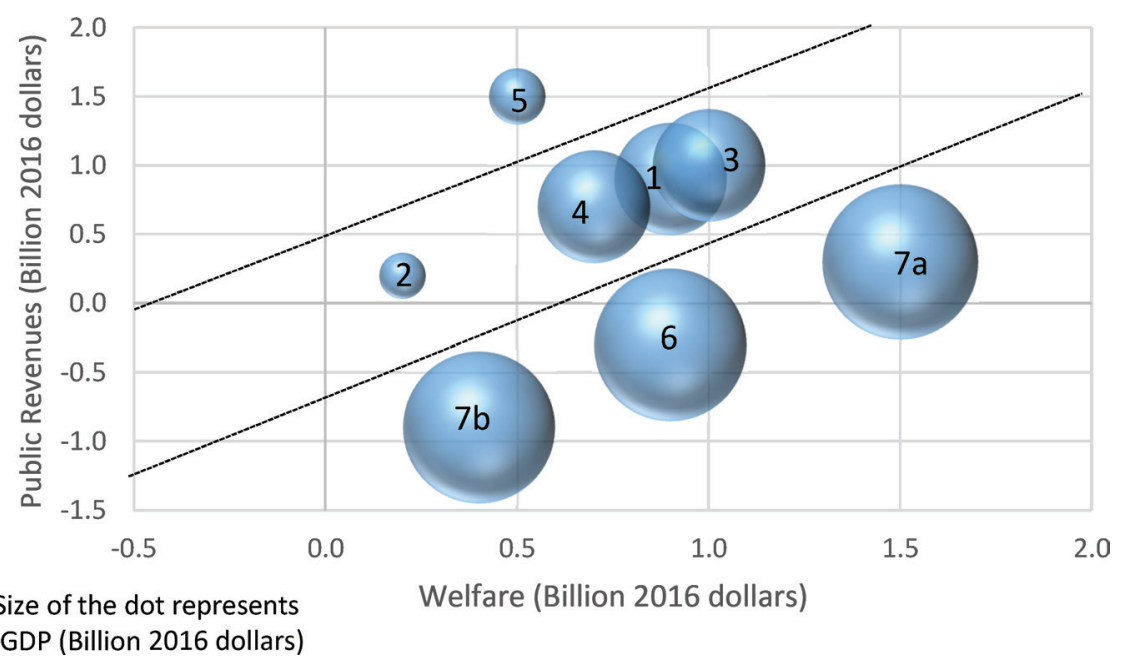

FIGURE 3

Impact of policies on welfare, public revenues, and GDP.

\subsection{Impacts of escalating policies up to their maximum technical limit}

The previous section compared the impact of a consistent escalation of policies in order to demonstrate the relative efficacy of each. However, policymakers might also be interested in the potential economic and environmental impacts of these policies if they were escalated to their maximum technical limit. Table 5 illustrates this. Note that both Policy 1 and Policy $5^{18}$ have no evident technical limit. To compare these policies in this section, we impose a limit of 696,000 bpd as this is the limit for the largest alternative that could be achieved (Policy 2).

\section{TABLE 5}

Annual impacts of escalating the policies to their maximum (in thousand bpd, billion 2016 dollars and millions of tons).

\begin{tabular}{lccccc}
\hline Policy & Oil exports & Welfare & GDP & Public revenues & $\mathrm{CO}_{2}$ \\
\hline 1 Production of oil & $696^{*}$ & 7.8 & 10.5 & 8.2 & +2.5 \\
2 Natural gas imports & 696 & 1.2 & 1.3 & 1.3 & -38 \\
3 Efficiency of gas power plants & 102 & 1.3 & 1.6 & 1.4 & -14 \\
4 Renewable technology & 367 & 2.9 & 5.6 & 3.1 & -49 \\
5 Price of domestic oil & $696^{*}$ & 2.6 & 0.5 & 14.5 & -94 \\
6 Productivity of electricity & 96 & 1.1 & 2.9 & -0.5 & -10 \\
7a Productivity of oil (scrapping) & 82 & 1.6 & 2.5 & 0.3 & -11 \\
7b Productivity of oil (hybrids) & 139 & 0.5 & 4.1 & -1.8 & -19 \\
\hline
\end{tabular}

${ }^{*}$ Note, for the sake of comparison, the maximum level of oil exports for Policy 1 and Policy 5 is assumed to be the same as Policy 2.

18. We analyze the potential impact of the substantial increase in administered prices of gasoline and electricity in January 2018. This increase was accompanied by the Citizen's Account policy in December 2017, which allows for a public direct transfer to low income households, as a way to counter the effects of the price rises. This combination of policies is similar to the one labelled in this study as Policy 5. In particular, we simulate an increase in the administered price of oil of $80 \%$ in the model, consistent with the average increase in electricity tariffs and the increase in gasoline 91 -octane by $80 \%$. The simulation shows that this policy would increase oil exports by 724,000 bpd and welfare by $\$ 2.6$ billion annually in the long run. In addition, it would reduce $\mathrm{CO}_{2}$ emissions by 97 million tons annually. 
Policies aimed at increasing energy efficiency (Policy 6, Policy $7 a$ and Policy $7 b$ ) have a relatively mild impact on oil exports and domestic carbon emissions even if pushed to their maximum, as they are difficult to escalate significantly. They also provide poor net public revenues due to their high costs. On the other hand, policies that are easier to escalate significantly and aim to reduce the use of oil in power generation (Policy 2 and Policy 4) can reduce oil consumption significantly and have a positive impact on welfare and public revenues. Policy 1 (at the assumed maximum) has a large impact on welfare, GDP and net public revenues due to the low cost of increasing oil production. However, this policy has its downsides: a large increase in domestic carbon emissions, the potential difficulties of agreeing and coordinating such a policy with the other members of OPEC to ensure the stability of the oil market. Policy 5 (again, at the assumed maximum) has the largest impact on public revenues. However, the required increase in domestic oil prices by $75.3 \%$ to reach the assumed saving would harm non-energy output and limit the potential welfare gain.

\section{* 5. CONCLUSIONS}

This study explores the long-run impacts of different policies aimed to curb oil consumption in Saudi Arabia and increase oil revenues from exports. The domestic price of oil is administered and below the international price, creating an opportunity to generate economic value. To undertake the research, we use a general equilibrium model for a small open economy where the international price of oil depends on the level of Saudi exports. To the best of our knowledge, this is the first study to address this issue from a long-run general equilibrium perspective.

We discuss seven policies aimed at reducing long-run oil consumption and increasing long-run oil exports. As outlined, to reduce the use of oil in electricity generation, Saudi Arabia could import LNG for power generation, deploy renewable energy, or increase the technical efficiency of natural gas plants. These policies benefit from the gap between the domestic and international prices of oil. An alternative way to reduce oil consumption could be to increase the efficiency of electricity and oil consumption. Finally, it could be possible to reduce oil consumption and increase oil exports by increasing the domestic prices of oil. For the sake of completeness, we also consider a policy for increasing oil production, as this is a more obvious way to increase oil exports.

Our analysis of these policies leads to the following insights:

- Policies designed to curb oil consumption have positive impacts in terms of households' welfare and on Saudi carbon emissions. The cost of the policies and their impact on productivity are also critical.

- The fall in the international price due to the increase in oil exports reduces the potential welfare gain from these policies.

- Policies aimed at increasing energy efficiency have limited scalability, and, consequently, the potential positive impacts at macroeconomic scales are relatively small.

- Shifting power generation from oil to natural gas has a positive impact on the Saudi economy even if the natural gas is imported.

- The gross welfare gains of energy efficiency projects, either in the use of electricity or in transportation, are higher than those aimed at replacing the use of oil for power generation with natural gas or renewables. However, energy efficiency projects tend to be more expensive than initiatives to reduce oil in power generation. 
- Welfare gains for all the policies studied range between a minimum of $\$ 6$ and $\$ 56$ per barrel of oil saved. These policies reduce the level of domestic $\mathrm{CO} 2$ emissions by around $370 \mathrm{~kg}$ per barrel saved, excluding the policy that increases the share of natural gas in the generation mix.

Although our analysis considers the individual implementation of each policy, the government could carry out a number of programs simultaneously. The implementation of any of the policies studied in this paper changes the domestic consumption of oil across different activities and sectors, altering the potential benefits of the other policies. This is quite clear in the case of an increase in domestic oil prices. The gap between international prices and administered domestic prices creates the opportunity to consume oil more efficiently. An increase in the domestic price of oil makes this opportunity less clear. Consequently, further work is needed on the optimal combination of policies.

\section{* ACKNOWLEDGMENTS}

An earlier version of this paper was presented and discussed at the 35th USAEE/IAEE North American Conference, Houston, Texas, U.S. and at the International Energy Workshop 2018, Goteborg, Sweden. We are grateful to the participants of these forums as well as various KAPSARC colleagues for their comments and suggestions. We are also grateful to two anonymous referees and the editor for their comments and suggestions, which have helped to improve this paper considerably. Nonetheless, the authors are responsible for all errors and omissions. Furthermore, the views expressed in this paper are those of the authors and do not necessarily represent the views of their affiliated institutions. Baltasar Manzano acknowledges the financial support of the Spanish Ministry of Economy and Competitiveness and FEDER through grant ECO2015-68367-R (MINECO/FEDER).

\section{References}

Atalla, T. N., A. Gasim, and L. C. Hunt. 2018. "Gasoline demand, pricing policy, and social welfare in Saudi Arabia: A quantitative analysis.” Energy Policy 114: 123-133. https://doi.org/10.1016/j.enpol.2017.11.047.

Blazquez, J., L. C. Hunt and B. Manzano. 2017. "Oil Subsidies and Renewable Energy in Saudi Arabia: A General Equilibrium Approach.” The Energy Journal, 38(S1): 29-45. https://doi.org/10.5547/01956574.38.SI1.jbla.

Bloomberg New Energy Finance. 2015. H2 2015 LCOE EMEA Outlook.

BP. 2017. Statistical Review of the World Energy. (http://www.bp.com/statisticalreview)

Boogen, N. 2017. "Estimating the potential for electricity savings in households." Energy Economics 63: 288-300. https://doi.org/10.1016/j.eneco.2017.02.008.

Burniaux, J.M. and Chateau, J. 2014. "Greenhouse gases mitigation potential and economic efficiency of phasing-out fossil fuel subsidies.” International Economics 140: 71-88. https://doi.org/10.1016/j.inteco.2014.05.002.

Cuenot, F. 2009. " $\mathrm{CO}_{2}$ emissions from new cars and vehicle weight in Europe; How the EU regulation could have been avoided and how to reach it?" Energy Policy 37(10): 3832-3842. https://doi.org/10.1016/j. enpol.2009.07.036.

Dartanto, T. 2013. "Reducing fuel subsidies and the implication on fiscal balance and poverty in Indonesia: A simulation analysis." Energy Policy 58: 117-134. https://doi.org/10.1016/j.enpol.2013.02.040.

De Miguel, C. and B. Manzano. 2006. "Optimal oil taxation in a small open economy." Review of Economic Dynamics 9(3): 438-454. https://doi.org/10.1016/j.red.2005.10.004.

De Santis, R. A. 2003. “Crude oil price fluctuations and Saudi Arabia’s behavior.” Energy Economics 25(2): $155-173$. https://doi.org/10.1016/S0140-9883(02)00106-8. 
Electricity and Cogeneration Regulatory Authority (ECRA) (2015). Activities and Achievements of the Authority in 2014.

Golosov, M., J. Hassler, P. Krusell and A. Tsyvinski. 2014. "Optimal taxes on fossil fuel in general equilibrium.” Econometrica, 82(1): 41-88. https://doi.org/10.3982/ECTA10217.

Gonand, F. 2016. "Impacts of Higher Energy Efficiency on Growth and Welfare Across Generations in Saudi Arabia” KAPSARC Discussion paper, KS-1657-DP051A. Available at: https://www.kapsarc.org/wp-content/uploads/2016/10/KS-1657-DP051A-Impact-of-Higher-Energy-Efficiency-on-Growth-and-Welfare-Across-Generations-in-Saudi-Arabia.pdf.

Gonand, F., F. J. Hasanov, and L. C. Hunt 2019. "Estimating the Impact of Energy Price Reform on Saudi Arabian Intergenerational Welfare using the MEGIR-SA Model" The Energy Journal 40(3): 55-77. https://doi. org/10.5547/01956574.40.3.fgon.

Hahn, R. and R. Metcalfe. 2016. "The Impact of Behavioral Science Experiments on Energy Policy." Economics of Energy \& Environmental Policy 5(2): 27-44. https://doi.org/10.5547/2160-5890.5.2.rhah.

Hamilton, J.D. 2009. "Understanding Crude Oil Prices." The Energy Journal 30(2): 179-206. https://doi. org/10.5547/ISSN0195-6574-EJ-Vol30-No2-9.

Helman, C. 2012. "Saudi Arabia to Become an Oil Importer? Here is How Can They Can Avoid it." Forbes, September 4, 2012.

IHS Global Insights. 2010. Assessment of the effectiveness of scrapping schemes for vehicles economic, environmental, and safety impacts. Report prepared for European Commission, DG Enterprise and Industry.

Instituto para la Diversificación y el Ahorro de Energía. 2017. Informe cierre PIVE 8.

Kim, I. M. and P. Loungani. 1992. "The role of energy in real business cycle models." Journal of Monetary Economics 29(2): 173-189. https://doi.org/10.1016/0304-3932(92)90011-P.

Liu, Y. 2014. "Household demand and willingness to pay for hybrid vehicles." Energy Economics 44: 191-197. https://doi.org/10.1016/j.eneco.2014.03.027.

Molina, M. 2014. “The best value for America's energy dollar: a national review of the cost of utility energy efficiency programs". In American Council for an Energy-Efficient Economy.

Nakov, A. and N. Galo 2013. "Saudi Arabia and the oil market." The Economic Journal 123, no. 573: $1333-1362$. https://doi.org/10.1111/ecoj.12031.

Petroleum Economist. 2017. Saudi Arabia: LNG ahead, October 30. (Accessed March 12, 2018 http://www. petroleum-economist.com/articles/midstream-downstream/lng/2017/saudi-arabia-lng-ahead).

Plante, M. 2014. "The long-run macroeconomic impacts of fuel subsidies.” Journal of Development Economics 107: 129-143. https://doi.org/10.1016/j.jdeveco.2013.11.008.

Pierru, A., J. L. Smith, and T. Zamrik. 2018. "OPEC's Impact on Oil Price Volatility: The Role of Spare Capacity." The Energy Journal 39(2): 173-196. https://doi.org/10.5547/01956574.39.2.apie.

Renewable Energy Project Development Office. 2017. (Accessed August 1, 2017 https://www.powersaudiarabia. com.sa/web/index.html).

Rotemberg, J. J. and M. Woodford. 1996. "Imperfect Competition and the Effects of Energy Price Increases on Economic Activity." Journal of Money, Credit and Banking 28(4): 549-577. https://doi.org/10.2307/2078071.

Saudi Arabian Monetary Authority. 2017. Annual Statistics 2016. (Accessed October 13, 2017 http://www.sama. gov.sa/en-US/EconomicReports/Pages/YearlyStatistics.aspx)

Schwanitz, V. J., F. Piontek, C. Bertram and G. Luderer. 2014. "Long-term climate policy implications of phasing out fossil fuel subsidies." Energy Policy 67: 882-94. https://doi.org/10.1016/j.enpol.2013.12.015.

U.S. Energy Information Administration. 2016. Updated capital cost estimates for utility scale electricity generating plants. (https://www.eia.gov/analysis/studies/powerplants/capitalcost/pdf/capcost_assumption.pdf)

Wall Street Journal. 2016. Barrel Breakdown. (Accessed June 4, 2017. http://graphics.wsj.com/oil-barrelbreakdown/).

Wesseh Jr, Presley K., and Boqiang Lin. 2017. "Options for mitigating the adverse effects of fossil fuel subsidies removal in Ghana." Journal of Cleaner Production 141: 1445-1453. https://doi.org/10.1016/j.jclepro.2016.09.214. 